Western University Scholarship@Western

FIMS Publications

Information \& Media Studies (FIMS) Faculty

January 2012

\title{
Social Media for Academic Libraries
}

David J. Fiander

Western University, dfiander@uwo.ca

Follow this and additional works at: https://ir.lib.uwo.ca/fimspub

Part of the Library and Information Science Commons

Citation of this paper:

Fiander, David J., "Social Media for Academic Libraries" (2012). FIMS Publications. 27.

https://ir.lib.uwo.ca/fimspub/27 
Chapter 11: Social Media for Academic Libraries

David J. Fiander

Western Libraries

University of Western Ontario

1151 Richmond St.

London,

Ontario N6A 3K7

CANADA

dfiander@uwo.ca

\section{Abstract}

This chapter discusses the value of the academic library engaging with its users via social media sites like Facebook and Twitter. The chapter provides some background on research into how libraries have experimented with using Facebook for outreach and how the user community has responded. It gives a brief outline of the process for creating a rich Facebook page for an academic library system and tips for how to market a Facebook page or Twitter account, and how to use social media accounts to promote the library's services. Finally, it provides some guidance for how an academic library should think about policies for posting to social sites by staff, and how to deal with user comments on social media sites.

Keywords: libraries, outreach, marketing, promotion, Facebook, Twitter, YouTube 


\section{Introduction}

In 2006, OCLC found that library users "do not see a role for libraries in constructing social sites, and most would not be very likely to contribute content" (De Rosa, Cantrell, Havens, Hawk, and Jenkins, 2007, p. 5-1). It is probably still true today that the library's users would not participate in a social community constructed by the library and hosted on the library's website, but librarians no longer think about social media as something that the library should build and provide, rather as a platform with which they should engage. Librarians are going out to the social media sites on the Internet that the users are already active on and connecting with their communities where they are: Twitter, Facebook, YouTube, and more. But using these services to connect with the community and promote the library is different from using them personally, and it is also very different from the way library administrations are accustomed to communicating with their users. Twitter isn't a PA system, and Facebook is not a monthly newsletter; they are not only immediate: they are interactive, and interacting with the users on these sites can alienate rather than attract users if the sites are viewed as "marketing channels", rather than places where conversations take place.

Social network sites are not broadcast media; they are places to engage in conversations with your community. Using social media like Twitter, blogs, and Facebook to promote your library and engage your community is different from sending out newsletters, and putting up posters and whiteboards to announce events. Social media is, first and foremost, social: users expect to be involved in a dialogue, and a steady stream of content (at a reasonable pace) is better than a weekly update of the "What's New" items on the library's website (Levine, Locke, Searls, and Weinberger, 2000). 


\section{Overview of social media types and sites}

"Social media" is a broad term that encompasses many different services and ways of interacting. Each service has particular strengths and weaknesses, develops a particular user community, and has a distinct style of interaction. Libraries beginning to look at producing a social media strategy will have to be prepared to be (almost) everywhere, but "being everywhere" does not mean that every platform needs distinct content. Because each service is used for different types of communication, each type of content (such as videos, library news, or announcements) will have a "natural" medium; other social media platforms will usually direct users to that platform.

\subsection{Blogging}

In an institutional setting, blogging has two primary roles. First, it can take on the role of the traditional library newsletter and announcements board, but with neither the publication delays of the former's typical monthly schedule nor the tendency of the latter to go unnoticed. Second, it can be used by individual librarians to communicate with their constituents, deepening the relationship between the librarians and their users and personalizing "the library" in a way that often leads to increased use of the library, especially by undergraduates (Goss, 2010).

The two most popular blog platforms are WordPress (http://www.wordpress.com) and Blogger (http://www.blogger.com). Both WordPress and Blogger provide a "hosted" blog platform, which means that a library can quickly create a blog and begin posting content online without having to be responsible for managing a server itself. The default blog addresses for both of these services identify the platform that is hosting the blog (that is, "http://myblog.wordpress.com" and "http://myblog.blogspot.com" respectively), but it is 
possible to configure both systems so that the library's blog has an institutional address like "http://blog.library.school.edu"; Blogger provides this service at no charge, but WordPress charges a fee for this service. WordPress also places advertising on the pages of free blogs, but those ads can be eliminated (for a fee, of course). If your library uses one of these platforms for blogging, then you should arrange to have appropriate institutional addresses for your blogs. Aside from the slightly unprofessional impression that having a "blogspot.com" or "wordpress.com" address gives, linking the blogs directly to an institutional address ensures not only that the blog is unambiguously recognized as being produced by the library, but also that if the library decides to change blog service or to start hosting the blog directly on the library's own server, then the address of the blog won't change.

If your library (or school) is managing its own website on a dedicated web server using a content management system (CMS), then it probably supports blogging directly; the IT staff responsible for managing the CMS will be able to explain what the blogging options available are. Alternatively, there are several options available for installing specialized blogging software on a local server, including WordPress. This is the most complex option, but it is also the most flexible, and gives the library the most control over how to organize the library's and librarians' blogs, and also provides options for managing user comments in keeping with Anil Dash's guidelines for managing an online community (see section 3.2 below). Again, the local IT staff will be able to discuss what options are available.

\subsection{Microblogging / Twitter}

"Microblogging" is the general term for the concept of posting very short status updates as popularized by services like Tumblr (http://www.tumblr.com) and Twitter 
(http://www.twitter.com). Twitter was originally conceived of by its creators as a broadcast medium: a way to share quickly where one is; and what one is doing, thinking, or feeling. It is still used that way, but like any human communication channel, it has become conversational.

For libraries, Twitter should be viewed primarily as a customer service medium. Use it to announce service outages and problems with the heat on the fifth floor. It should also be used for cross-promotion: to share links to the latest news items posted on the library's homepage and to new blog posts by subject librarians. Aside from such announcements, Twitter is also useful for tracking what the library's users are saying about it. If your library has a bulletin board with feedback forms on it, then you are only gathering feedback from those users who bother to come to the library and try to find that very physical feedback medium; even remote users are unlikely to go to the library's website to try to find an online feedback form. People use Twitter to rant and rave about what's going on in the moment, so library staff are more likely to find out about the heating problems on the fifth floor from Twitter than they are from any other channel, if the library is tracking what people are saying. Another advantage that Twitter has over the traditional feedback bulletin board is that Twitter is immediate and conversational: library staff can respond directly to the users at the moment of the complaint, even if only to commiserate and let them know that the facilities department is working on getting the heat working again. While the library's "official" presence on Twitter will account for much of the interaction with users, individual staff members should also be empowered to respond to comments and questions that they see in their normal use of Twitter. The way that social media depends on the voices of individuals within an organization will be discussed further in section 3 below. 


\subsection{Video Sharing}

A video sharing site is not going to create the same type of social community that might form on Facebook, nor will it be as active a communication channel as Twitter, but creating an account on a video sharing site and using it to host instructional videos makes it simpler for a library to embed videos in its own website, offloads the complications of hosting video and makes sure it is compatible with all the various browsers and operating systems out there, and gives your users a forum in which to discuss the videos. Video sharing sites like YouTube (http://www.youtube.com) and Vimeo (http://www.vimeo.com) make it simple for a library to share video tutorials with its users. Both sites contain a rich collection of demonstrations of bibliographic tools like RefWorks and Zotero, databases like PubMed and JSTOR, and even library tours.

YouTube and Vimeo are essentially the same in terms of video sharing and community forum features. Their primary differences are related to downloading videos and video licensing options. YouTube gives video creators the option of assigning either a standard copyright "all rights reserved" license to their videos, or a Creative Commons "Attribution" license; Vimeo, however, gives creators the full range of Creative Commons licenses, allowing the creators to fine-tune how they are willing to let their videos be reused (for more information about Creative Commons licenses, see http://www.creativecommons.org). While it is unlikely that users would be interested in downloading a library's introduction to using RefWorks, Vimeo does let the video creator decide whether viewers may download it; YouTube does not allow viewers to download videos at all. 
Finally, YouTube is famous for unpleasant comments (the web comic strip xkcd shows the general attitude toward YouTube comments quite clearly (Munroe, 2006)). Be prepared to remove comments or block abusive users, and keep in mind Anil Dash's guidelines for managing an online community (see section 3.2, below).

\subsection{Facebook}

Much of the library literature discusses creating a Facebook profile for the library and then adding students and faculty as "friends" (see, for examples: Connell, 2009; Dickson and Holley, 2010, or Mack, Behler, Roberts, and Rimland, 2007). Aside from the fact that research has shown that students find this practice invasive and verging on "stalking" (Connell), it is also in violation of Facebook's terms of use, which require that profiles belong to real people, and that the profile be identified by that owner's real name. Libraries that have created profiles for their organizations have found their accounts deleted without warning when Facebook has become aware of the violation. These older articles were all written prior to Facebook introducing the newer "fan page" (already renamed by Facebook to just "page"), which is distinct from a profile page, and which can be named after any person (real or imaginary), or organization, and which can be created by anybody. A page allows users to "Like" the subject of the page, without giving

the administrators of the page access to all the users' private information (which is another one of the disadvantages of a library "friending" students: it exposes the students' personal information to the library in a way that neither the student nor the library is comfortable with). In order to simplify the discussion, I will refer to people who "Like" a page as fans of that page, even though Facebook is downplaying that terminology. 


\section{Creating a Facebook Page}

Before you begin the page creation process, you need to gather some information. All of these settings can be changed later, but it is better if you can configure the page appropriately from the beginning. Make sure you have a suitable photo or logo that represents your library, have identified the appropriate contact email address and phone number for the library (the contact information is not necessarily for a reference service, but for any questions that users of the Facebook page might direct towards the library), and decided on the name you will use for the Facebook page. If your institution has several library branches, you should also consider creating a page for the library system as well as pages for each of the branches. Given the size of Facebook, think carefully about the name you're going to use so that it is simple for your users to find you: if your library is named "Kresge" or "Carnegie", or if you are creating the page for the music library branch, consider including the school's name in the name of the page to distinguish it from the many other Kresge, Carnegie, or music libraries in the world. Including the school's name also ensures that when people search for the school, they will also see the page(s) that belong to the library.

Facebook provides several different types of pages depending on the object of the page, and each type has different options for the information that the page administrator can provide to visitors to the page. An academic library might reasonably be an educational "Company, Organization, or Institution"; a library "Local Business or Place"; or even a library "Entertainment" page. Because of the detailed informational options available, including the library's address, phone number, and hours opening, the "Local Business or Place" category of page is probably the most suitable type of page to create. Providing these details enables Facebook to provide a map link on your page, indicate in real time whether the library is open 
when people look at your page, and will let users accessing Facebook via their smartphones to phone the library easily.

Creating a Facebook page is a simple process, once you are logged in, and have managed to navigate to Facebook's "Create a Page" page (in fact, getting to the "Create a Page" form may be the most difficult part of the process). The easiest way to get to the "Create a Page" link, is from a pre-existing "Page":

1. Switch to your personal profile page by clicking on your name at the top of the Facebook page, then click on the "Info" link under your profile photo.

2. On your profile page, click on the link for any of the pages associated with your employer, education, or interests. Click on the "Create a Page" button on upper right corner of that page. You're now ready to begin creating the Facebook page for your library.

3. Select the category of page you want to create. There are options for creating "Library" pages under both "Local Business or Place" and "Entertainment", as well as an "Education" option under "Company, Organization, or Institution". Because "Local Business or Place" provides the most detailed information, it is probably the best choice.

4. Enter the name of your library. If you are creating a "Business or Local Place" page, then finish the form with the library's address and telephone number (this telephone number doesn't need to be the reference desk, but should be a number that is most likely to be answered whenever the library is open).

5. The next part of the process sets up some basic information about the library. First, upload a photo that is representative of your library. Use a shot of the exterior, or of your imposing reference hall, or anything that your users will recognize as being your library. 
6. The next step that Facebook recommends is "Get Fans", which it proposes that you do by inviting your personal friends to like the page, to like the page yourself, and to post the new page on your wall. Start spreading the word about the page by liking it yourself, and recommending it to library staff who are on Facebook. Promoting your page within Facebook like this is just the beginning. You will also need to spend time making your community aware of Facebook via other channels as well.

7. The last step in the page creation process is "Basic Info". Enter the URL for your library's website, and provide a basic description of the library in the "About" page. Consider the audience you are targeting on Facebook: the "About" section of your Facebook page should be short and suitable for your users, especially the students; it is not the place for the library's vision or mission statements.

Once you've completed the "Basic Info", you will end up on your newly created page, looking at the "Get Started" section, which will remind you to complete any of the initial steps that you skipped, and give you some suggestions about how to promote the page. Click on the "Wall" link on the left side of the page, under the profile picture, to see what normal Facebook users see. You should probably post a "welcome to the library's page" message to the Wall to kick things off.

There are many options available to you as the administrator that give you control over how your page is displayed to users, and what users are allowed to do on the page. Click on the "Edit Page" button in the upper right corner of the screen to start exploring them. You should resist every librarian's natural tendency to very carefully control who can comment on the library's Facebook page. There will be few users initially, and the best way to encourage more users to join is by allowing for free flowing discussions to take place. Only if you start running into 
problems with inappropriate content should you think about placing restrictions on how your community can interact with the page.

The "Edit Page" screen also allows you to set a general contact email address that will be displayed on the page, and list the library's hours. If you use Facebook's structured format for listing the library hours, then that page will automatically display whether the library is open when users visit the page. Also, make sure to indicate whether or not your library provides valet parking.

If you created pages for the library system and for each of the branches, then the library system page should "like" all of the branches, and the branches should all "like" at least the system's page, in order to cross link the different parts of the system, and to help promote the various pages. Individual branch pages may "like" each other if there is an obvious relationship between them (for example, the map library might "like" the social sciences library, which houses the geography monographs and journals).

Finally, add some additional administrators to the page. Not only does this help distribute the workload associated with keeping the page up to date, but it also ensures that there's always somebody available to manage the page when the creator is unavailable.

\section{Promoting and Managing the Library's Facebook Page}

Once your library has a Facebook page, the next challenge is acquiring fans: posting news and events to your Facebook page does no good if nobody is listening. Unlike individual Facebook profiles, your library page cannot actively "friend" users (which is for the best, since Connell (2009) concluded that users found being "friended" by the library invasive): your page will accumulate fans organically, and slowly over time. As the number of fans grows, each new user 
will expose your page to their friends by interacting with your page. Start by promoting the page with library staff, especially front-line service staff and instructional librarians. These staff can mention the page to users during their normal interactions, and can promote it as a way to stay current with what's going on in the library. As well, liaison librarians will often be Facebook "friends" with faculty in the departments for which they are responsible, and this too can help spread the word about the page. Promote your library's Facebook page the same way you would promote any other website: with a news item on the library's homepage; by having librarians talk about it in classes they teach, and service staff mention it during interactions with users at the desk; and by putting up a poster near the library's entrance. Once you have made some fans on Facebook, then the information and links that you post to the library's Facebook page will also act as promotion: fans will share links with their friends, which will draw the friends' attention to your page, and may lead to more members of your community liking your page.

Facebook is not a medium for which the dictum that "if you build it, they will come" applies. A successful Facebook page depends not just on promotion, making your users aware of it, but also in activity on the page. Jacobson (2011, p. 88) found that "Librarians must be aware that using Facebook as a tool requires a lot of attention, and, if a library cannot commit to updating its Facebook page at least once a week or more, it may not be a very useful or successful tool." A static Facebook page will not attract fans, and an active Facebook page is a far better channel for communicating with your users that a "What's New" box on the library's homepage, because many of your users, both students and faculty, will spend more time in Facebook than they do on the library's homepage.

The library's Facebook page is primarily a marketing tool: a way to connect with your user community and promote the library's facilities and services, and to advertise events. When 
librarians first started trying to incorporate Facebook into their outreach practices, many of them created Facebook apps that allowed users to add catalogue searching or chat reference services to their profiles. It isn't clear how many users (rather than library staff) actually took advantage of these apps, and research has shown that the users see Facebook as a social activity: it is a break from the academic work that the library represents (Connell, 2009). Since the library's users will be spending more time on Facebook than on the library's homepage, information about the library's services, and its stream of news announcements, need to be visible to the Facebook community. Institutional blog posts and the "What's New" items on the library's website should also be posted to Facebook as "notes". Do not use Facebook just to post links back to the library's website: users are more likely to engage with the content on Facebook than they are on the library's website: they will share or "like" items they find interesting or of value with their friends, and they will post comments and ask questions about items that are relevant to them, but not if all they see on Facebook is a headline and a link. Unless the headline is immediately relevant, users will not bother to click through to the library's website to read the body of the message.

Facebook should also be used to advertise open workshops, tours, author readings, and any other special events taking place in, or sponsored by, the library. Don't just announce the events on the library's Facebook page like all the other news items posted there, but create "Facebook events" for them. Facebook events have several advantages for users: as already discussed, Facebook events will be more more visible to the library's fans than the announcements posted on the library's website; it is simpler for users to RSVP (although Facebook RSVPs do not necessarily translate into confirmed attendance). When users do RSVP, they automatically share the fact that they are planning to attend the event with all of their Facebook friends, thereby 
multiplying the exposure of the event. Facebook makes it simple for users to add events to their online calendars, which may also translate event RSVPs into attendance.

With over half a billion users, Facebook is the 800 pound gorilla of social networking sites. As such, it will inevitably be a critical, if not the central, component of the library's social media planning. To reinforce what Jacobson (2011) found, an inactive Facebook page, one that isn't being updated at least once or twice a week, is a dead Facebook page: users will not bother to become fans of a page that isn't being maintained. However much librarians might like to think that the library's homepage is the most important way to communicate with their online and remote users, those users visit Facebook daily, and only rarely look at the library's website. Make sure that your library is available where your users are.

\subsection{Making Social Platforms Work Together: What Goes Where?}

If the library has jumped into social media with both feet and created a Twitter account, Facebook page, and YouTube channel, the library now must decide what information gets posted to each platform. Each platform has its own distinct culture, and each is best suited for certain types of information. But not only do you need to figure out what is the appropriate platform for each posting, you also need to determine how best to cross-promote your postings. For example, it is clear that the new RefWorks tutorial video belongs on the library's YouTube channel, but what else should the library do to promote it?

As already discussed, Twitter is a customer service platform: suitable for listening for comments from your community, and for quick announcements about short-term issues, or reminders of things that are about to happen; Facebook works well for longer "What's New" types of information, and for posting information about upcoming events in a way that makes it 
easy for users to RSVP, add to their calendars, and share the events with their friends; and YouTube is for videos. Beyond this basic level of promotion, your social media accounts can also be used to share information about each other, which will multiply the effect of each of them, and help them all attract more attention.

When you post a video to YouTube, it should be shared on your Facebook page and announced on Twitter. You should also repost the video when it's appropriate during the academic year. For example, a few weeks before classes end, and term papers are due, would be a good time to remind your users about your "How to use RefWorks to create your bibliography" video. Similarly, when you post a news item or event to Facebook, you should also share that on Twitter. Not only does this get the information about the particular news item or event out to your Twitter community, but it also promotes your Facebook page to that community. In general, Twitter users are more accepting of frequent updates that Facebook users: not everything that you tweet needs to be posted on Facebook.

Twitter and Facebook are both arranged chronologically, with the newest postings appearing most prominently on their respective pages. Facebook will push what it thinks are "interesting" items to the top of the page, but for the most part this will not affect the way that items on the library's page will appear to your users, so it shouldn't be depended on. This focus on chronology implies that when you post announcements about far off events (for interpretations of "far off" ranging from next week to next month) or long running events, such as special exhibits, then many of your Twitter followers or Facebook fans might miss it, or might forget that it's happening. In general, Twitter and Facebook users will not mind if you repost the event every so often as a reminder that it's coming, but there is a difficult balance to be maintained: if you post 
the same item too often (or in the case of Facebook, just post things too often in general), then you will be considered a spammer, and will lose followers and fans.

Aside from information about the library itself, Facebook and Twitter can be used to draw the attention of fans and followers to other related events or news items that they might find interesting. For example, if the campus bookstore is having an author reading, the library Facebook page might share the event on its wall, so fans of the library will find out about it. Take care, however: too much activity on the page might be viewed by users as spam, or clogging up their newsfeed with too much library and not enough real friends. Make sure that any supplementary postings are relevant to the library community (that is, they're literary or research focused in some way) and that they are spaced out in time.

\section{Social Media Policies and Procedures}

Academic libraries tend to be highly structured organizations, with very detailed policies and procedures covering all of their day-to-day workings. If social media are going to be part of the communication process for informing your users about the library, and responding to their questions and concerns, then you will need to develop policies and procedures for doing so. The difference between a social media policy and most of the other policies developed by the library is that the social media policy needs to be flexible enough to enable staff to share information in a timely fashion, usually without a lot of internal review, and to allow staff to respond to users' comments promptly. In the world of social networks, there is no "official spokesperson" for the library: everybody who works for the library is talking to the users. But then, that's what happens today: "The mail clerk describes the [library's] strategy to the stranger next to him on the bus, and then provides a critique" (Levine et al., 2000, p. 107). Of course, that's not entirely true; 
there is still an official communication channel, which the library uses for announcements about building hours and other services, new library initiatives, and documenting policies about food or off-campus access. What has changed on the modern campus is that now your users expect to be able to interact with this official channel, rather than just passively receive a stream of broadcast messages. The other difference between traditional library communication practices and the social environment is that the library has less control. The community is holding conversations about the library on Facebook, Twitter, and their own blogs already; all the library can do is try to join those conversations as just another participant, and create a space for the library to communicate its point of view. Thus, there are two types of policies that must be developed: one covering issues related to posting to social media sites as the library, which includes not just distributing announcements, but also responding to users' comments; and one giving guidance related to moderating and managing comments that users have made on the library's own website, or on the library's Facebook page.

\subsection{Policies and Procedures for Posting as the Library}

The policies for posting to social media via the library's accounts will vary depending on the particular platform. Facebook updates will probably mirror the official "what's new" news items from the library's website, but responding to comments that users make on Twitter about the library, and interacting with fans of the library on Facebook require a more personal touch than that provided by standard news announcements, and they also require a much more timely response than can be afforded by the schedule of the typical library communications committee. 
Specific policies must always be coloured by the local institutional environment; however, some things to keep in mind when developing policies and procedures for posting to social media as the library include:

1. Try not to be too formal in responding to comments. Even if you are only going to be pointing to a formal policy document, don't be harsh. If you are perceived to be "slapping down" a user, then you won’t get very many "Likes."

2. If there is a group of people who will be sharing the responsibility of responding on social media, especially on Twitter, set up a schedule so that only one person is "on duty" for any given day (or whatever time period makes sense locally). If more than one person is monitoring and responding, then users may end up confused getting two answers from "the library".

3. You don't need to respond to every comment or question about the library. It is especially dangerous to be seen as trying to have the last word in a discussion. Do keep track of all the comments that you see, though, because if there's a trend in the comments, then that trend might be better addressed by a news item or longer Facebook posting, or to use as evidence for a change in library policy.

\subsection{Comment Policies for Libraries' Social Media}

Many libraries are concerned about comments on their websites. There is a common feeling that as supporters of free expression, any attempt to control or moderate the user discussion on blogs or Facebook pages will be considered censorship, and somewhat hypocritical. These libraries are, of course, assuming that there will be a lot of discussion and community engagement on their blogs and website. While the library's goal is to have an active community participating 
online, its website, blog, or Facebook page will probably not get as much traffic as the staff think.

Developing comment moderation policies does not mean that the library is practising censorship; the policies ensure that the library's social media presence is respectful, and (mostly) on topic. Anil Dash (2011) provides simple (but potentially labour intensive) guidelines that will ensure that your website is supportive of engaged users interested in true dialog:

1. Develop community policies about acceptable behaviour, and enforce them

2. Dedicate staff time to monitoring and interacting with your users.

3. Require users to sign their comments with a "persistent" identifier.

4. "Have the technology to easily identify and stop bad behaviour." (section "This is a solved problem", para. 7)

Dash (in his final sentence) concludes by saying that "if you don't [follow these guidelines], you're making the web a worse place. And it's your fault."

\section{Community Acceptable Behaviour Policies}

The "acceptable behaviour" policy that a site defines for users who are commenting on a website does not need to be as comprehensive as the typical library acceptable use policy for patrons using the library's public PCs or wifi. Dash recommends that the policy be short, written in plain language, and flexible, so that "people aren't trying to nitpick the details of the rules." Librarians are often concerned about being seen as "censors", or as trying to shut down free speech, when the topic of website moderation is raised, but blocking spammers and ensuring that a discussion stays on topic without ad hominem attacks or insults is not censorship. Just 
remember that disagreeing with you, or arguing with other members of the community, is not inappropriate behaviour (Niles, 2010).

\section{Monitoring and Interacting with Your Users}

Managing a community is labour intensive, but it is essential to ensure that your site can attract and maintain a community of users and isn't taken over by comment spam. When you first launch your library's Facebook page or blog, it won't have very much traffic, so monitoring the comments will not take very much time, but be prepared to increase the amount of staff time devoted to working with the community as it becomes more active. As important as moderating the users on your social media is interacting with them: the point of social media is to be social. The staff involved in managing the library's social media presence are ambassadors for the library. Answer users' questions, help them find what they're looking for, and guide the conversations that arise. Sometimes this can lead to concerns about patron confidentiality; I recommend leaving this to the discretion of the staff involved in the conversation. It is important to remember that if a patron asked a question in public, then they probably won't mind getting an answer in public. If you would rather answer the question privately, then post a followup comment asking them for contact information so you can send your answer to them separately.

\section{Users Must Have Persistent Identifiers}

Users do not necessarily have to provide their "real names" (Hinkley (2011) provides a good overview of while pseudonyms are valuable online) but requiring persistent identifiers of some sort simplifies tracking patterns of inappropriate behaviour and may reduce "drive-by" trolling. ${ }^{1}$ Facebook, Twitter, and most large social media platforms already implement persistent accounts, so this is of concern only if you will be hosting a blog on the library's website or one of the blog 
hosting services mentioned earlier. A simple way for academic libraries to implement this policy on locally hosted blogs would be to require users to $\log$ in with their standard campus identity. Such a policy does preclude members of the general community from engaging with the library's social media, however, so if your library is interested in outreach to the local community and enabling engagement, especially with alumni who may no longer have valid campus computer accounts, this option may not be feasible. Consult local IT staff to see what your options are for implementing persistent identifiers for locally hosted blogs.

\section{Identifying and Stopping Bad Behaviour}

If you are lucky, your Facebook page will be awash in conversations, your blog postings will inspire heated debates about the relative merits of the authors you profile, and there will be so much traffic that it will be difficult for your staff moderators to keep up. Or, more likely, the staff responsible for monitoring and participating in your various social endeavours will only be able to devote time to the task during the normal workday, amongst all their other responsibilities. And when your moderators are most distracted is when somebody will make himself known and start posting unpleasant comments that are in violation of your community guidelines. Most platforms provide a way for users of the site to "flag" comments by other users as inappropriate. This will allow you to move quickly to deal with spam and harassment even when you don't have time to be fully involved in the conversations that are taking place. Just make sure to remember that people will flag things they don't like, even if they're not inappropriate.

While setting policies for staff posting to social networks as the library, and for dealing with users commenting on Facebook and library blogs, are important, don't attempt to cover every possible eventuality in your policies before launching your social media presence. The new 
social network environment requires flexibility on the part of the library administration, and trust in the library staff who will be managing the library's presence. Having basic guidelines and ensuring that staff are empowered to respond promptly and helpfully will make the experience better for both the library staff and the community, and will ensure that the library's social network grows.

\section{Conclusions}

Librarians often talk about being where our users are. In academic libraries, this has translated into holding reference office hours in departmental offices, student centres, and even residence halls (Rudin (2008) surveys the literature regarding reference outreach). Today, the users are on Twitter and Facebook, but they're not looking for the librarian there: social networking is first and foremost social. Users are not expecting research help via Twitter or a catalogue search box in Facebook, but they are open to finding out about library services and events via their social channels, and they may appreciate knowing that library staff are paying attention when they complain about "service quality" problems in the library via their social networks, if the library responds promptly, honestly, and as a human being rather than as an institution. Do not expect your new social networking presence to gain a lot of followers quickly, but if promoted well, and used appropriately, it will become an effective way to inform your community about events and services, and to provide customer support services.

\section{Notes}

1. "In Internet slang, a troll is someone who posts inflammatory, extraneous, or off-topic messages in an online community, such as an online discussion forum, chat room, or blog, 
with the primary intent of provoking readers into an emotional response or of otherwise disrupting normal on-topic discussion.” (“Troll”, 2011, para. 1)

\section{References}

Connell, R. S. (2009). Academic libraries, Facebook and MySpace, and student outreach: A survey of student opinion. portal: Libraries and the Academy, 9(1), 25-36. doi:10.1353/pla.0.0036

Dash, A. (2011). If your website's full of assholes, it's your fault. A blog about making culture [Blog post]. Retrieved from http://dashes.com/anil/2011/07/if-your-websites-full-of-assholesits-your-fault.html

De Rosa, C., Cantrell, J., Havens, A., Hawk, J., and Jenkins, L. (2007). Sharing, privacy and trust in our networked world [Report]. Dublin, OH: OCLC. Retrieved from http://www.oclc.org/reports/sharing/

Dickson, A., and Holley, R. P. (2010). Social networking in academic libraries: the possibilities and the concerns. New Library World, 111(11/12), 468-479. doi:10.1108/03074801011094840

Goss, H. (2010). Extending library instruction: Using Blogger to collaborate, connect, and instruct. Journal of Library \& Information Services in Distance Learning, 4(4), 166-184. doi:10.1080/1533290X.2010.524831

Hinkley, K. (2011). On pseudonymity, privacy and responsibility on Google+ [Blog post]. TechnoSocial. Retrieved from 
http://www.marrowbones.com/commons/technosocial/2011/07/on_pseudonymity_privacy_an d_re.html

Jacobson, T. B. (2011). Facebook as a library tool: Perceived vs. actual use. College \& Research Libraries, 72(1), 79 -90.

Levine, R., Locke, C., Searls, D., and Weinberger, D. (2000). The Cluetrain Manifesto: The end of business as usual. Cambridge, MA: Perseus Books.

Mack, D., Behler, A., Roberts, B., and Rimland, E. (2007). Reaching students with Facebook: Data and best practices. Electronic Journal of Special and Academic Librarianship, 8(2). Retrieved from http://southernlibrarianship.icaap.org/content/v08n02/mack_d01.html

Munroe, R. (2006). YouTube [Cartoon]. xkcd.com. Retrieved from http://xkcd.com/202/

Niles, R. (2010). If you can't manage comments well, don't offer comments at all [Blog post]. Retrieved from http://www.ojr.org/ojr/people/robert/201003/1836/

Rudin, P. (2008). No fixed address: The evolution of outreach library services on university campuses. Reference Librarian, 49(1), 55-75.

Wikipedia (2011). Troll (Internet). Retrieved from http://en.wikipedia.org/wiki/Troll_(Internet) 